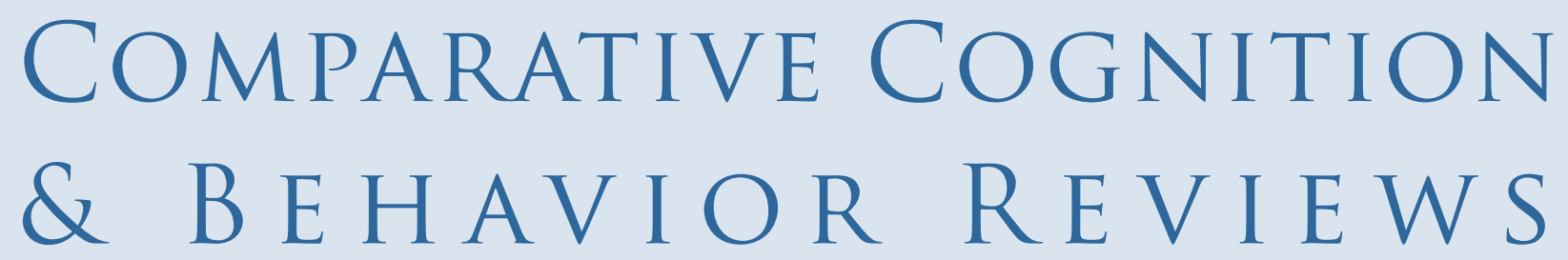

\title{
Clarifying Contrast, Acknowledging the Past, and Expanding the Focus
}

\section{Jeffrey M. Pisklak}

University of Alberta

\author{
Margaret A. McDevitt \\ McDaniel College
}

\author{
Roger M. Dunn \\ San Diego State University
}

This commentary highlights, clarifies, and questions various historical and theoretical points in Thomas Zentall's review "What Suboptimal Choice Tells Us About the Control of Behavior." Particular attention is paid to what Zentall refers to as the "unskilled gambling" paradigm. We acknowledge additional contributions to the study of suboptimal choice and clarify some theoretical issues foundational to a behavioral approach. We also raise important questions about Zentall's use of the concept of "contrast," how it is related to previous contrast research, and how it fails to extend a very similar explanation that predates it.

\section{Keywords: suboptimal choice, conditioned reinforcement, contrast}

Zentall's (2019) review sets out to describe "what suboptimal choice tells us about the control of behavior." It is useful to have different types of suboptimal behavior discussed in one article, and although we are grateful for the focus on suboptimality, our commentary focuses on a few difficulties with his assessment. At the outset, the historical framework for suboptimal choice appears to have been recast for the purposes of this review. For example, Zentall writes,

Those of us who study the behavior of animals assume that they have evolved to maximize their success (e.g., at finding food) and much of learning theory (Skinner, 1938; Thorndike, 1911) is based on this premise. Animals select those responses that lead to the increased probability of reinforcement over those that do not. When animals' behavior is consistent with this theory, it strengthens our belief in the validity of the theory. (p. 1)

The assumption that animals "have evolved to maximize their success (e.g., at finding food)" (p. 1) is independent of behaviorist views on learning and not, as Zentall asserts, foundational to it. Neither of the two classic works he cites (Skinner, 1938; Thorndike, 1911, both digitally archived in the public domain) defines behavior in terms of any kind of maximization. Moreover, the subsequent claim that "animals select those responses that lead to the increased probability of reinforcement" (p. 1) is a further distortion of the behaviorist position. On both a phylogenetic and ontogenetic level, it is the environment, not the organism, that is selecting behavior (Baum, 2008; Skinner, 1981). To suppose otherwise would require the invocation of para-mechanistic hypotheses and theories (e.g., intentionality). In this context, Zentall's use of the term reinforcement seems more akin to a layperson's conception of reward. For Skinner (1953, p. 72), reinforcement is a functional description of an environment-behavior relation, not a theory to be falsified. If a pigeon learns to select an option that leads to food $20 \%$ of the time instead of an option that leads to food $50 \%$ of the time, then that $20 \%$ option is, by definition, the more reinforcing of the two. The question for researchers is, why is it the more reinforcing of the two (i.e., what are the controlling 
variables)? We emphasize these distinctions not only for reasons of historical accuracy but because a functional analysis underlies the explanation of suboptimal choice discussed here.

Although Zentall's review does provide a context for the summary of recent work in his laboratory, a reader may wish to look elsewhere for an introduction to a more general understanding of the phenomena described in this review and in the earlier article (Zentall, 2016). One example most relevant to our work is the treatment of what is referred to as "unskilled gambling" in both articles. A reader could be forgiven for believing that the study of this form of suboptimal choice began recently, but it should be made clear that much of Zentall's own work described in the present review replicates and, at times, extends much earlier work. The initial investigation of suboptimal choice (Kendall, 1974) built on the study of observing behavior (e.g., Wilton \& Clements, 1971). Kendall's work survived considerable skepticism from contemporaries (see, e.g., Fantino, Dunn, \& Meck, 1979). The phenomenon has since been studied extensively by others (see McDevitt, Dunn, Spetch, \& Ludvig, 2016, and Vasconcelos, Machado, \& Pandeirada, 2018, for reviews from learning and optimal foraging perspectives, respectively).

The review describes three phenomena covered in an earlier review and three additional phenomena. Zentall concludes his review by stating that "in all six of the examples of suboptimal or biased choice by pigeons presented in the present article together with those presented in Zentall (2016), the suboptimal behavior can be explained in terms of evolved heuristics" (p. X), but the phenomena are described at various times throughout his review in terms of more than just heuristics, as both optimal foraging and learning principles are appealed to regularly throughout the article. Even within a given theoretical frame, the discussion is confusing at times. Zentall offers a hypothesis for suboptimal choice that appears to redefine the term contrast and, as discussed next, bears little resemblance to how the term is used in the extensive literature on behavioral

Author Note: Jeffrey M. Pisklak, Department of Psychology, P217 Biological Sciences Building, University of Alberta, Edmonton, Alberta, Canada T6G 2 E9.

Correspondence concerning this article should be addressed to Jeffrey M. Pisklakat pisklak@ualberta.ca.

Guest edited by Michael F. Brown. contrast. In addition, the concept has received only selective use by Zentall and his colleagues in the past to account for some suboptimal results but not others (e.g., Smith, Bailey, Chow, Beckmann, \& Zentall, 2016; Smith \& Zentall, 2016; Stagner, Laude, \& Zentall, 2012). Thus, it is curious that this explanation is presented in the present review without qualification. The understanding of any phenomenon is enhanced when alternative explanations are presented and their relative strengths and weakness are explored. The integrity of psychological research faces significant challenges (Chambers, 2017) and is better served when the goal is not to argue for a particular point of view but to present a balanced assessment of the evidence as a whole (Johnson, 2013).

\section{Contrast Revisited}

Zentall (2019) introduces contrast as a "third factor" in suboptimal choice:

Although the predictive value of the conditioned reinforcer that follows choice of each alternative, independent of its probability of occurrence, appears to predict choice (Smith \& Zentall, 2016), there is evidence suggesting that there may be a third factor (Case \& Zentall, in press; McDevitt et al., 2016) ... positive contrast between the expected value of reinforcement following choice of the suboptimal alternative and the value of the conditioned reinforcer that follows on half of the trials. (p. 2)

This is not a traditional interpretation of contrast. Within the literature on learning and behavior, the term contrast has been used most often to describe an effect on behavior that occurs when a change in the rate of reinforcement in one component of a multiple schedule produces an opposite change in the rate of response in another component (Reynolds, 1961; Williams, 1983). In a typical demonstration of positive contrast, baseline responding is established on a two-component multiple schedule with equivalent schedules of reinforcement. When the second component is changed to an extinction schedule in a second phase, the rate of responding in the first (target) component increases, demonstrating positive anticipatory contrast.

Demonstrations of contrast have typically employed multiple schedules with variable-interval reinforcement schedules, response-independent transitions between components, and unvarying component order. Figure 1 shows the positive contrast procedure used by Williams (1992) in which Component A produced reliably higher rates of responding than Component $\mathrm{B}$ because extinction in Component $\mathrm{X}$ always followed $\mathrm{A}$. This positive 
contrast procedure is very different from the suboptimal choice procedure, which typically uses concurrent schedules of reinforcement and probabilistic determination of the following stimulus and schedule. An example of a suboptimal alternative (based on Stagner \& Zentall, 2010 ) is shown in Figure 2. A single peck to an initiallink stimulus leads to one of two terminal-link stimuli. When red is presented, food follows after $10 \mathrm{~s}$, but when green is presented, no food is delivered.

Zentall (2019) uses the term contrast to explain the increased choice of a signaled suboptimal alternative. This is a curious use of the term because contrast, in its traditional sense, has been seen as a pattern of behavior and not an explanation of it. That aside, considering the many differences in the two procedures, it is not clear how the same mechanism would operate in both. Previous research has shown that the increase in response rate in the presence of the individually presented stimulus generated by the positive contrast procedure does not reflect increased value. That is to say, when probe trials provided a choice between Components A and B in Figure 1, Component B was reliably preferred despite the higher response rate in the presence of Component $\mathrm{A}$ when presented in the multiple schedule (Williams, 1991, 1992). Thus, value and response rate are in opposition, and these two dependent measures cannot be assumed to measure the same thing. Zentall cites the work of Case and Zentall (2018), and they, in turn, cited Williams's
(1983) review of behavioral contrast in their explanation of suboptimal preference, but it is not clear how that work is relevant. Thus, we have the following question about Zentall's use of the term to explain suboptimal choice: Specifically, in what way is positive behavioral contrast related to suboptimal preference, and what is the evidence that the same mechanism occurs in both procedures?

\section{Contrast as Conditioned Reinforcement?}

Another interpretation of Zentall's use of the term contrast is that it is essentially a repackaging of the conditioned reinforcement explanation offered by Dunn and Spetch (1990; Spetch, Belke, Barnet, Dunn, \& Pierce, 1990) that is now formally called the SiGN model (McDevitt et al., 2016).

According to Dunn and Spetch (1990),

A response in the initial link of the $50 \%$ chain is followed by either a timeout of $50 \mathrm{~s}$ or food delivery in $50 \mathrm{~s}$. In this case, the onset of the terminal-link stimulus correlated with food delivery signals a delay reduction and can be expected to reinforce the initial-link response. (p. 214)

In Zentall's (2019) terms, "preference for the suboptimal alternative may result from positive contrast between the expected value of reinforcement following choice of the suboptimal alternative and the value of the conditioned reinforcer that follows on half of the trials" (p. 2).

Figure 1. Schematic of positive behavioral contrast procedure used by Williams (1992). Each multiple schedule was assigned to either the left or right response key of a pigeon operant chamber and presented individually in a randomized fashion.

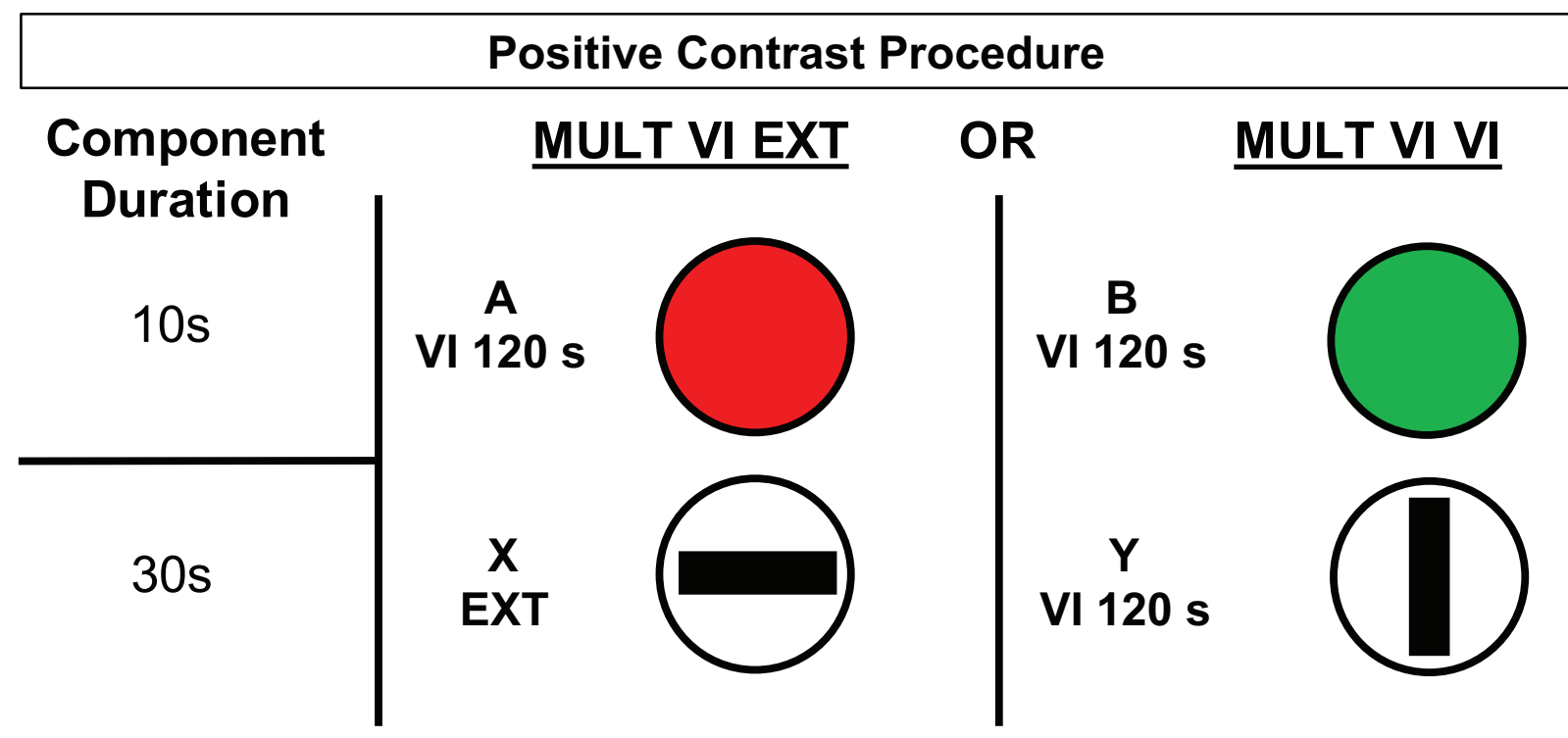




\section{Suboptimal Alternative}

\section{FR 1}

FT $10 \mathrm{~s}$

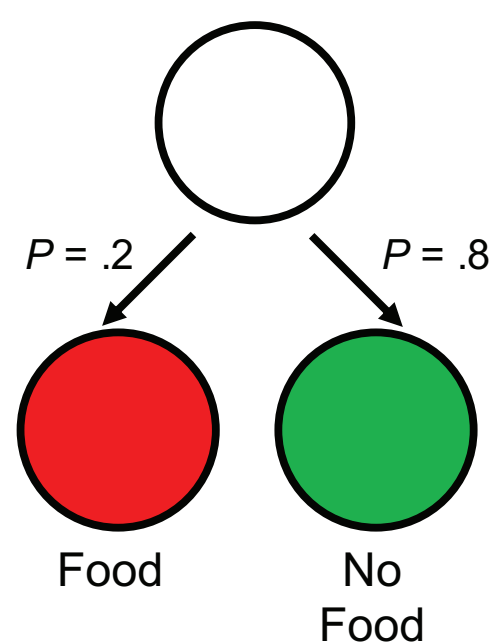

EXT $10 \mathrm{~s}$

Figure 2. Schematic of the suboptimal choice alternative's chained schedule, as described in Stagner and Zentall (2010).

There also appears to be similarity in the analysis of the optimal alternative:

A terminal-link stimulus may function as a conditioned reinforcer only when its onset signals a reduction in delay over that signaled by other stimuli in the local context of that alternative. With FR 1 initial links, onset of the terminal-link stimulus on the $100 \%$ alternative should not function as a conditioned reinforcer because it does not signal a reduction in delay over that signaled by the initial-link peck that produced it. (Spetch et al., 1990, p. 220)

Zentall (2019) argues something very similar:

The fact that $50 \%$ signaled reinforcement was preferred over $100 \%$ reinforcement (Case \& Zentall, 2018) suggests that there may also be contrast between the expected value of reinforcement $(50 \%$ expected) and the obtained value of reinforcement $(100 \%$ obtained) given choice of the suboptimal alternative, whereas there would be little contrast involving the optimal alternative (100\% reinforcement expected and 100\% reinforcement obtained). (p. 14)

Zentall continues: "The hypothesis that contrast between what is expected and what is signaled to occur is essentially the same as what McDevitt et al. (2016) refer to as the signal for good news" (p. 14). We agree with this assessment but also note that this explanation dates back to Dunn and Spetch (1990), which leads us to the following question: In what way, if any, is Zentall's contrast explanation different from the one proposed by Dunn and Spetch? At present the two appear to be indistinguishable. If contrast is in fact "essentially the same," as the SiGN hypothesis, which explains suboptimal choice in terms of conditioned and primary reinforcement, then we are left to wonder how contrast could constitute a "third factor" of suboptimal choice. Correctly identifying Zentall's contrast explanation as conditioned reinforcement would aid comparison with other models of conditioned reinforcement neglected by the present review (e.g., Cunningham \& Shahan, 2018; Mazur, 1997).

In this commentary we have attempted to fill in some of the gaps in Zentall's (2019) presentation of suboptimal choice by highlighting earlier work on which it has been based, as well as recognizing some contemporary treatments that show promise in extending our understanding of the mechanisms involved. In addition, we raise significant questions about Zentall's contrast explanation that require answers if it is to be considered a unique and worthwhile explanation of suboptimal choice.

\section{References}

Baum, W. M. (2008). Understanding behaviorism: Behavior, culture, and evolution (2nd ed., pp. 59-79). Malden, MA: Wiley-Blackwell.

Case, J. P., \& Zentall, T. R. (2018). Suboptimal choice in pigeons: Does the predictive value of the conditioned reinforcer alone determine choice? Behavioural Processes, 157, 320-326. doi:10.1016/j.beproc.2018.07.018

Chambers, C. (2017). The seven deadly sins of psychology: A manifesto for reforming the culture of scientific practice. Princeton, NJ: Princeton University Press.

Cunningham, P. J., \& Shahan, T. A. (2018). Suboptimal choice, reward-predictive signals, and temporal information. Journal of Experimental Psychology: Animal Learning and Cognition, 44, 1-22. doi:10.1037/xan0000160

Dunn, R., \& Spetch, M. L. (1990). Choice with uncertain outcomes: Conditioned reinforcement effects. Journal of the Experimental Analysis of Behavior, 53, 201-218. doi:10.1901/jeab.1990.53-201 
Fantino, E., Dunn, R., \& Meck, W. (1979). Percentage reinforcement and choice. Journal of the Experimental Analysis of Behavior, 32, 335-340. doi:10.1901/jeab.1979.32-335

Johnson, J. A. (2013, July 22). Are research psychologists more like detectives or lawyers? Psychology Today. Retrieved from https://www.psychologytoday.com/us/blog/cui-bono /201307/are-research-psychologists-more-detectives -or-lawyers-0

Kendall, S. B. (1974). Preference for intermittent reinforcement. Journal of the Experimental Analysis of Behavior, 21, 463-473. doi:10.1901/jeab.1974.21-463

Mazur, J. E. (1997). Choice, delay, probability, and conditioned reinforcement. Animal Learning \& Behaviour, 25, 131-147. doi:10.3758/BF03199051

McDevitt, M. A., Dunn, R. M., Spetch, M. L., \& Ludvig, E. A. (2016). When good news leads to bad choices. Journal of the Experimental Analysis of Behavior, 105, 23-40. doi:10.1002/jeab.192

Reynolds, G. S. (1961). Behavioral contrast. Journal of the Experimental Analysis of Behavior, 4, 57-71. doi:10.1901/jeab.1961.4-57

Skinner, B. F. (1938). The behavior of organisms: An experimental analysis. New York: AppletonCentury. Retrieved from Internet Archive website: https://archive.org/details/TheBehaviorOfOrganisms

Skinner, B. F. (1953). Science and human behavior. New York: Free Press.

Skinner, B. F. (1981). Selection by consequences. Science, 213, 501-504. doi:10.1126/science. 7244649

Smith, A. P., Bailey, A. R., Chow, J. J., Beckmann, J. S., \& Zentall, T. R. (2016). Suboptimal choice in pigeons: Stimulus value predicts choice over frequencies. PLoS ONE, 11(7), 1-18. doi:10.1371/journal.pone.0159336
Smith, A. P., \& Zentall, T. R. (2016). Suboptimal choice in pigeons: Choice is primarily based on the value of the conditioned reinforcer rather than overall reinforcement rate. Journal of Experimental Psychology: Animal Learning and Cognition, 42, 212-220. doi:10.1037/xan0000092

Spetch, M., Belke, T., Barnet, R., Dunn, R., \& Pierce, W. (1990). Suboptimal choice in a percentage reinforcement procedure: Effects of signal condition and terminal-link length. Journal of the Experimental Analysis of Behavior, 53, 219-234. doi:10.1901/jeab.1990.53-219.

Stagner, J. P., Laude, J. R., \& Zentall, T. R. (2012). Pigeons prefer discriminative stimuli independently of the overall probability of reinforcement and of the number of presentations of the conditioned reinforcer. Journal of Experimental Psychology: Animal Behavior Processes, 38, 446-452. doi:10.1037/a0030321

Stagner, J. P., \& Zentall, T. R. (2010). Suboptimal choice behavior by pigeons. Psychonomic Bulletin \& Review, 17, 412-416. doi:10.3758/PBR.17.3.412

Thorndike, E. L. (1911). Animal intelligence: Experimental studies. New York: Macmillan. Retrieved from Internet Archive website: https://archive.org/details/animalintelligen00thor /page/n5

Vasconcelos, M., Machado, A., \& Pandeirada, J. N. S. (2018). Ultimate explanations and suboptimal choice. Behavioural Processes, 152, 63-72. doi:10.1016/j.beproc.2018.03.023

Williams, B. A. (1983). Another look at contrast in multiple schedules. Journal of the Experimental Analysis of Behavior, 39, 345-384. doi:10.1901/jeab.1983.39-345

Williams, B. A. (1991). Behavioral contrast and reinforcement value. Animal Learning \& Behavior, 19, 337-344. doi:10.3758/BF03197894 
Williams, B. A. (1992). Inverse relations between preference and contrast. Journal of the

Experimental Analysis of Behavior, 58, 303-312. doi:10.1901/jeab.1992.58-303

Wilton, R. N., \& Clements, R. O. (1971). Observing responses and informative stimuli. Journal of the Experimental Analysis of Behavior, 15, 199-204. doi:10.1901/jeab.1971.15-199
Zentall, T. R. (2016). When humans and other animals behave irrationally. Comparative Cognition \& Behavior Reviews, 11, 25-48. doi:10.3819/ccbr.2016.110002

Zentall, T. R. (2019). What suboptimal choice tells us about the control of behavior. Comparative Cognition and Behavior Reviews, 14, 1-17. doi:10.3819/CCBR.2019.140001 